\title{
Study on water evaporation rate from indoor swimming pools
}

\author{
Ilona Rzeźnik ${ }^{1, *}$ \\ ${ }^{1}$ Poznan University of Technology, Institute of Environmental Engineering, ul. Berdychowo 4 \\ 61-131 Poznań, Poland
}

\begin{abstract}
The air relative humidity in closed spaces of indoor swimming pools influences significantly on users thermal comfort and the stability of the building structure, so its preservation on suitable level is very important. For this purpose, buildings are equipped with HVAC systems which provide adequate level of humidity. The selection of devices and their technical parameters is made using the mathematical models of water evaporation rate in the unoccupied and occupied indoor swimming pool. In the literature, there are many papers describing this phenomena but the results differ from each other. The aim of the study was the experimental verification of published models of evaporation rate in the pool. The tests carried out on a laboratory scale, using model of indoor swimming pool, measuring $99 \mathrm{~cm} / 68 \mathrm{~cm} / 22 \mathrm{~cm}$. The model was equipped with water spray installation with six nozzles to simulate conditions during the use of the swimming pool. The measurements were made for conditions of sports pools (water temperature $24^{\circ} \mathrm{C}$ ) and recreational swimming pool (water temperature $34^{\circ} \mathrm{C}$ ). According to the recommendations the air temperature was about $2^{\circ} \mathrm{C}$ higher than water temperature, and the relative humidity ranged from $40 \%$ to $55 \%$. Models Shah and Biasin \& Krumm were characterized by the best fit to the results of measurements on a laboratory scale.
\end{abstract}

\section{Introduction}

For years, there has been increase in the number of pools, in Poland. The new objects are usually indoor pools and they are built as aqua parks, recreational pools or swimming pools with additional attractions, so their offer is directed to wider community. In 2015 year there were 736 indoor swimming pools in Poland: 12 olympic pools, 66 sports pools $(25 \times 16 \mathrm{~m})$, 489 smaller pools (dimensions $25 \times 12,5 \mathrm{~m}$ ) and 169 training and recreational pools (min. $16 \mathrm{~m})$ [1]. The most important phenomenon, in swimming pools is the water evaporation process. The indoor humidity directly impacts on user's comfort and durability of buildings construction. Wherefore, the most important is calculation of vapor production, what is necessary to proper design of HVAC system. Too high air humidity causes a feeling of breathlessness among users and it intensifies corrosion of the building. The oversized ventilation system increases the investment and operational costs and may cause a sense of

\footnotetext{
*Corresponding author: ilona.rzeznik@put.poznan.pl
} 
coolness among users. To dimension of HVAC systems, the mathematical models describing the evaporation of water in the occupied and unoccupied indoor swimming pools are used.

There are many formulas for calculation the water evaporation rate in occupied and unoccupied swimming pools, but their results differ from each other [1-18]. Additionally the problem is estimation the influence of using intensity on vapor production [2]. The aim of the study was experimental verification of published formulas for calculation the water evaporation rate in indoor swimming pools.

\section{Mathematical modeling}

The water evaporation rate was calculated according to Dalton's law:

$$
\begin{gathered}
\dot{g}_{w}=\varepsilon \cdot\left(p_{w}^{\prime \prime}-p_{w}\right) \\
\text { or } \\
\dot{g}_{w}=\sigma \cdot\left(x^{\prime \prime}-x\right)
\end{gathered}
$$

where:

$\dot{g}_{w}$ - water evaporation rate $\left(\mathrm{kg} \cdot \mathrm{m}^{-2} \cdot \mathrm{h}^{-1}\right)$,

$\varepsilon, \sigma$ - evaporation coefficients $\left(\mathrm{kg} \cdot \mathrm{m}^{-2} \cdot \mathrm{h}^{-1} \cdot \mathrm{Pa}^{-1}\right)$,

$p_{w}^{\prime \prime}$ - water vapor partial pressure at water temperature in boundary layer at saturation state $(\mathrm{Pa})$,

$p_{w}$ - water vapor partial pressure at the air temperature $(\mathrm{Pa})$,

$x^{\prime \prime}$ - humidity content in boundary layer at water temperature $\left(\mathrm{kg} \cdot \mathrm{kg}^{-1}\right)$,

$x$ - humidity content for saturated air at pool temperature $\left(\mathrm{kg} \cdot \mathrm{kg}^{-1}\right)$.

Mass flow rate is given by:

$$
\dot{m}_{w}=\dot{g}_{w} \cdot F
$$

where:

$$
\begin{aligned}
& \dot{m}_{w} \text { - mass flow rate }\left(\mathrm{kg} \cdot \mathrm{h}^{-1}\right) \\
& F \text { - evaporation area }\left(\mathrm{m}^{2}\right) .
\end{aligned}
$$

The water evaporation phenomenon in swimming pools were studied in laboratory $[3,4,5]$ and in real conditions [6,7]. Based on the literature study, Shah [8] reported the area of examined swimming pools, which ranged from $0,073 \mathrm{~m}^{2}$ to $425 \mathrm{~m}^{2}$. Those pool differed not only in the area but also in their shape. Asdrubali [3], Moghiman \& Jodat [4] and Tang \& Etzion [5] conducted measurement in perpendicular pools, Sartori [9] in cylindrical.

The equations of mass flow rate in the swimming pool halls, which were experimental verified in this study are presented in table 1 and 2 . Differences in results are mainly due to the different way of calculating the evaporation factors $\varepsilon, \sigma$, which are a function of Sherwood and Schmidt number and turbulence level. 
Table 1. Equations of mass flow rate in unoccupied swimming pools

\begin{tabular}{|c|c|c|}
\hline Author & Equation & \\
\hline Malicki [10] & $\begin{array}{l}\qquad \quad \dot{m}_{w}=\frac{(a+0,0174 \cdot w) \cdot 760}{p_{b}} \cdot\left(p_{w}^{\prime \prime}-p_{w}\right) \cdot F \\
a=0,022 \text { for } \mathrm{t}_{\mathrm{pw}}<30^{\circ} \mathrm{C} \\
a=0,028 \text { for } \mathrm{p}_{\mathrm{pw}}<40^{\circ} \mathrm{C} \\
t_{p w}-\text { temperature of water surface }\left({ }^{\circ} \mathrm{C}\right) \\
w-\text { air velocity }\left(\mathrm{m} \cdot \mathrm{s}^{-1}\right) \\
p_{b}-\text { atmosphere pressure } \\
p_{w}^{\prime \prime}, p_{w}, p_{b}(\mathrm{mmHg})\end{array}$ & (4) \\
\hline Ferencowicz [11] & $p_{w}^{\prime \prime}, p_{w}, p_{b}(\mathrm{mmHg}) \quad \dot{m}_{w}=\frac{(22,9+17,4 \cdot w) \cdot 760}{\left(1000 \cdot p_{b}\right)} \cdot\left(p_{w}^{\prime \prime}-p_{w}\right) \cdot F$ & (5) \\
\hline Sprenger [12] & $\dot{m}_{w}=(25+19 \cdot w) \cdot\left(x^{n}-x\right) \cdot F$ & (6) \\
\hline Dienelt [2] & $\begin{array}{l}\quad \dot{m}_{w}=\left(30+14 \cdot w-0,26 \cdot t_{s}\right) \cdot\left(x^{\prime \prime}-x\right) \cdot F \\
t_{s}-\text { average air temperature }\left({ }^{\circ} \mathrm{C}\right) \\
t_{s}=\frac{\left(t_{w g}+t_{p h}\right)}{2} \\
t_{w g}-\text { temperature of boundary layer }\left({ }^{\circ} \mathrm{C}\right) \\
t_{p h}-\text { temperature of air in hall of pool }\left({ }^{\circ} \mathrm{C}\right) \\
w<1 \mathrm{~m} \cdot \mathrm{s}^{-1}\end{array}$ & (7) \\
\hline Biasin \& Krumm [13] & $p_{w}^{\prime \prime}, p_{w}(\mathrm{hPa}) \quad \dot{m}_{w}=\left[-0,059+\left(0,0105 \cdot \frac{p_{w}^{\prime \prime}-p_{w}}{1,333}\right)\right] \cdot F$ & (8) \\
\hline Shah [14] & $\begin{array}{l}\quad \dot{m}_{w}=K \cdot \rho_{w} \cdot\left(\rho_{p}-\rho_{w}\right)^{0,333} \cdot\left(x^{\prime \prime}-x\right) \cdot F \\
\left(\rho_{p}-\rho_{w}\right)<0 \rightarrow \rho_{w}-\rho_{p} \\
\left(\rho_{p}-\rho_{w}\right)>0,02 \rightarrow K=35 \\
\left(\rho_{p}-\rho_{w}\right)<0,02 \rightarrow K=40\end{array}$ & (9) \\
\hline Smith [7] & $\begin{array}{l}\qquad \dot{m}_{w}=\frac{70+0,35 \cdot w}{r} \cdot\left(p_{w}^{\prime \prime}-p_{w}\right) \cdot F \\
p_{w}^{\prime \prime}, p_{w}(\mathrm{hPa}) \\
r-\text { latent heat of vaporization of water }\left(\mathrm{kJ} \cdot \mathrm{kg}^{-1}\right)\end{array}$ & (10) \\
\hline Carrier [15] & $p_{w}^{\prime \prime}, p_{w} \mathrm{~W}(\mathrm{hPa}) \quad \dot{m}_{w}=\frac{42,6+37,6 \cdot w}{r} \cdot\left(p_{w}^{\prime \prime}-p_{w}\right) \cdot F$ & (11) \\
\hline VDI 2089 [13] & $\begin{array}{l}\qquad \dot{m}_{w}=\frac{\varepsilon \cdot\left(p_{w}^{\prime \prime}-p_{w}\right) \cdot F}{1000} \\
\varepsilon=5-\text { for peaceful surface of water } \\
p_{w}^{\prime \prime}, p_{w}(\mathrm{hPa})\end{array}$ & (12) \\
\hline
\end{tabular}


Table 2. Equations of mass flow rate in occupied swimming pools

\begin{tabular}{|c|c|c|}
\hline Author & Equation & \\
\hline Besler [16] & $\begin{array}{l}\qquad \dot{m}_{w}=2,8 \cdot \frac{(a+0,0174 \cdot w) \cdot 760}{p_{b}} \cdot\left(p_{w}^{\prime \prime}-p_{w}\right) \cdot F \\
a=0,022 \text { for } \mathrm{t}_{\mathrm{pw}}<30^{\circ} \mathrm{C} \\
a=0,028 \text { for } \mathrm{t}_{\mathrm{pw}}<40^{\circ} \mathrm{C} \\
p_{w}^{\prime \prime}, p_{w}, p_{b}(\mathrm{mmHg})\end{array}$ & (13) \\
\hline Labhom [13] & $L_{b}=(3 \div 3,5) \quad \dot{m}_{w}=L_{b} \cdot(25+19 \cdot w) \cdot\left(x^{\prime \prime}-x\right) \cdot F$ & (14) \\
\hline Kappler [2] & $\begin{array}{l}\qquad \dot{m}_{w}=k_{p} \cdot(25+19 \cdot w) \cdot\left(x^{\prime \prime}-x\right) \cdot F \\
k_{p}=1,10-\text { small private indoor swimming pools } \\
k_{p}=(1,10 \div 1,15)-\text { general purpose pools } \\
k_{p}=1,20-\text { school and hotel pools }\end{array}$ & (15) \\
\hline VDI 2089 [13] & $\begin{array}{ll}\varepsilon=20-\text { public pools } & \dot{m}_{w}=\frac{\varepsilon \cdot\left(p_{w}^{\prime \prime}-p_{w}\right) \cdot F}{1000} \\
\varepsilon=28-\text { recreational pools } & \\
p_{w}^{\prime \prime}, p_{w}(\mathrm{hPa}) & \end{array}$ & (16) \\
\hline Recknagel [17] & $\begin{array}{l}\qquad \dot{m}_{w}=\sigma \cdot\left(x^{\prime \prime}-x\right) \cdot F \\
\sigma=20-\text { general purpose pools } \\
\sigma=30-\text { pools with artificial wave }\end{array}$ & (17) \\
\hline Biasin \& Krumm [13] & $\begin{array}{ll}p_{w}^{\prime \prime}, p_{w}(\mathrm{hPa}) \\
N-\text { number of users }\end{array} \quad \dot{m}_{w}=\left[0,119+\left(0,01995 \cdot 6 \cdot \frac{N}{F}\right) \cdot \frac{p_{w}^{\prime \prime}-p_{w}}{1,333}\right] \cdot F$ & (18) \\
\hline Shah [18] & $\begin{array}{l}\dot{m}_{w}=\left(5,95 \cdot \frac{N}{F}+1,2\right) \cdot K \cdot \rho_{w} \cdot\left(\rho_{p}-\rho_{w}\right)^{0,333} \cdot\left(x^{\prime \prime}-x\right) \cdot F \\
\text { For } \quad \frac{F}{N}>45 \\
\dot{m}_{w}=\left(14,85 \cdot \frac{N}{F}+1\right) \cdot K \cdot \rho_{w} \cdot\left(\rho_{p}-\rho_{w}\right)^{0,333} \cdot\left(x^{\prime \prime}-x\right) \cdot F \quad(20) \\
\text { For } \frac{F}{N}>4,5 \div 4 \\
\quad \dot{m}_{w}=2,5 \cdot K \cdot \rho_{w} \cdot\left(\rho_{p}-\rho_{w}\right)^{0,333} \cdot\left(x^{\prime \prime}-x\right) \cdot F \\
\text { Dla } \quad \frac{F}{N}<4,5 \\
\left(\rho_{p}-\rho_{w}\right)<0 \rightarrow \rho_{w}-\rho_{p} \\
\left(\rho_{p}-\rho_{w}\right)>0,02 \rightarrow K=35 \\
\left(\rho_{p}-\rho_{w}\right)<0,02 \rightarrow K=40 \\
N-\text { number of users }\end{array}$ & $(21)$ \\
\hline
\end{tabular}




\section{Experimental procedure}

The tests were carried out in laboratory conditions, using model of indoor swimming pool, measuring $0,99 \mathrm{~m} / 0,68 \mathrm{~m} / 0,22 \mathrm{~m}$. The area of the water surface was $0,6732 \mathrm{~m}^{2}$ (fig. 1 ) and is in the range of pools area given by Shah[8]. Studied model was equipped with water spray installation with six nozzles to simulate conditions during the use of the swimming pool. The air provided to the pool chamber was pre-dried and heated. Temperature and relative humidity of air in the pool chamber during measurement were set at constant level and maintained by ventilation unit and duct heater. To heat the water in model of pool was used the flow heater controlled by thermostat.

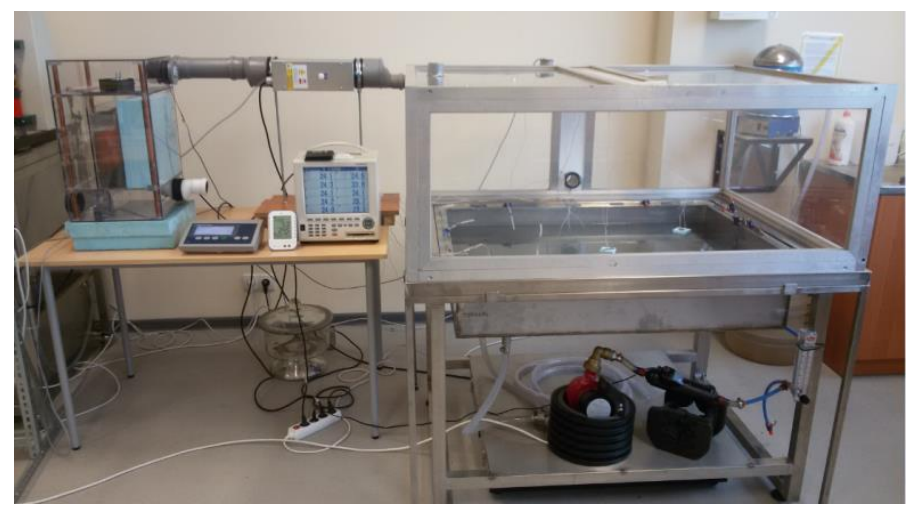

Fig. 1. Experimental stand.

Studied pool model was equipped in 12 thermocouples for air and water temperature measurements (accuracy $\pm 0,1^{\circ} \mathrm{C}$ ). The temperatures readings were collected and recorded by Omega RD-MV100 recorder. The LOG 32 TH recorder (measurement range 0-99\%; accuracy $\pm 3 \%$ ) was used to measure the relative humidity of air. Measurements of air velocity were made at point located $0,3 \mathrm{~m}$ above the water's surface as recommended [9], using the PL-135HAN anemometer, produced by Voltcraft (measurement range of 0,1-25,0 $\mathrm{m} \cdot \mathrm{s}^{-1}$; accuracy $\pm 5 \%$ )

The pan of swimming pool model was put on electronic laboratory scale ICS425, produced by METTLER TOLEDO (accuracy $\pm 1 \mathrm{~g}$ ). This allowed for the determining the mass of evaporated water. The measurements were made for conditions of sports pools (water temperature $24^{\circ} \mathrm{C}$ ) and recreational swimming pools (water temperature $34^{\circ} \mathrm{C}$ ). According to the recommendations the air temperature was about $2{ }^{\circ} \mathrm{C}$ higher than water temperature [3], and the relative humidity ranged from $40 \%$ to $55 \%$, as recommended [3,9]. Air velocity above surface of water was at constant level $0,1 \mathrm{~m} \cdot \mathrm{s}^{-1}$ and typical for these experiments [3].

\section{Results and discussion}

Results of the measurements were compared with values of water evaporation rate calculated according to equations (4-21). The calculated water evaporation rate were expressed per $1 \mathrm{~m}^{2}$ water's surface. The value for unoccupied sports swimming pool are shown in Fig. 2 and for recreational swimming pool are shown in Fig. 3. 


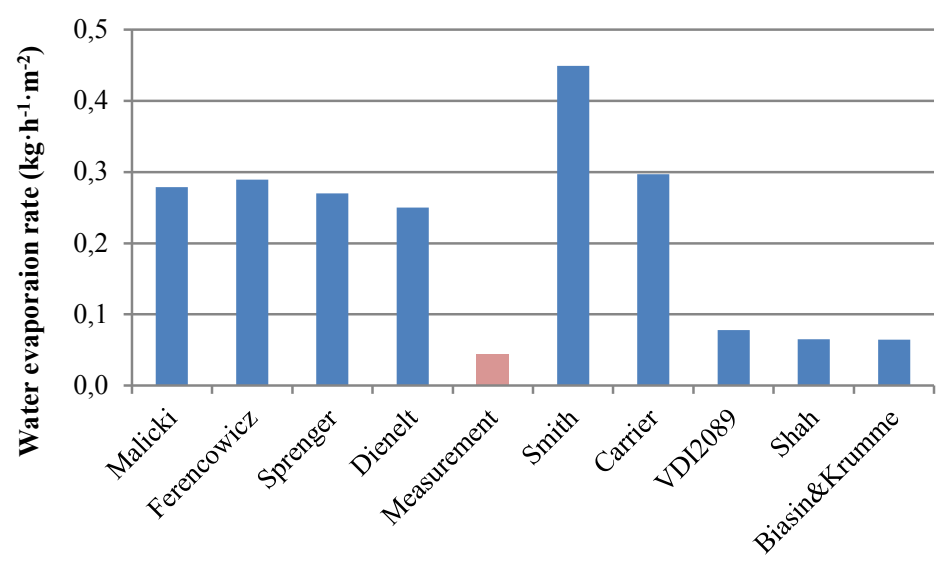

Fig. 2. Water evaporation rate in unoccupied sports swimming pools, with conditions described above.

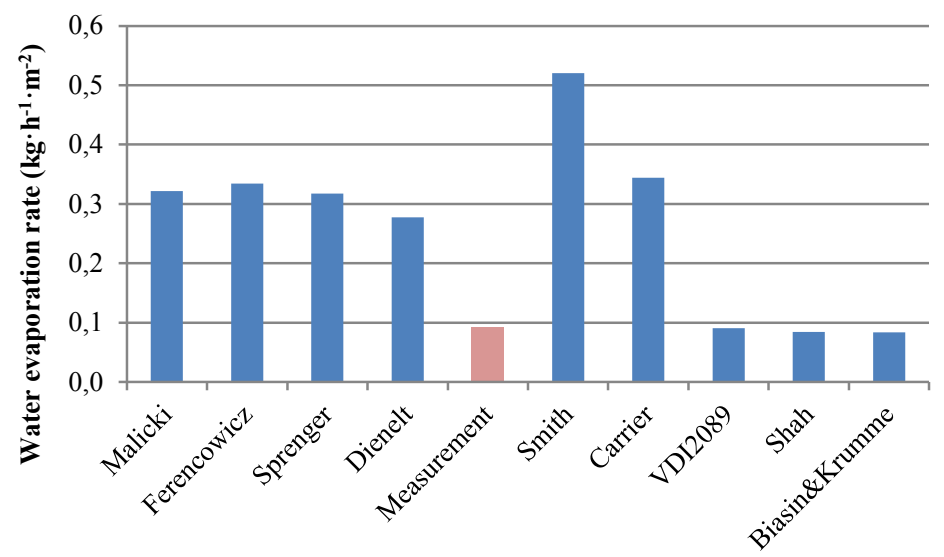

Fig. 3. Water evaporation rate in unoccupied recreational swimming pools, with conditions described above.

During study for occupied swimming pools was simulated the intensity of use at six level. The number of level was equal to the number of nozzles used during experiment. The results of comparisons between experimental data and the values calculated using published equation are shown in fig. 4 for sports swimming pools and in fig. 5 for recreational. 


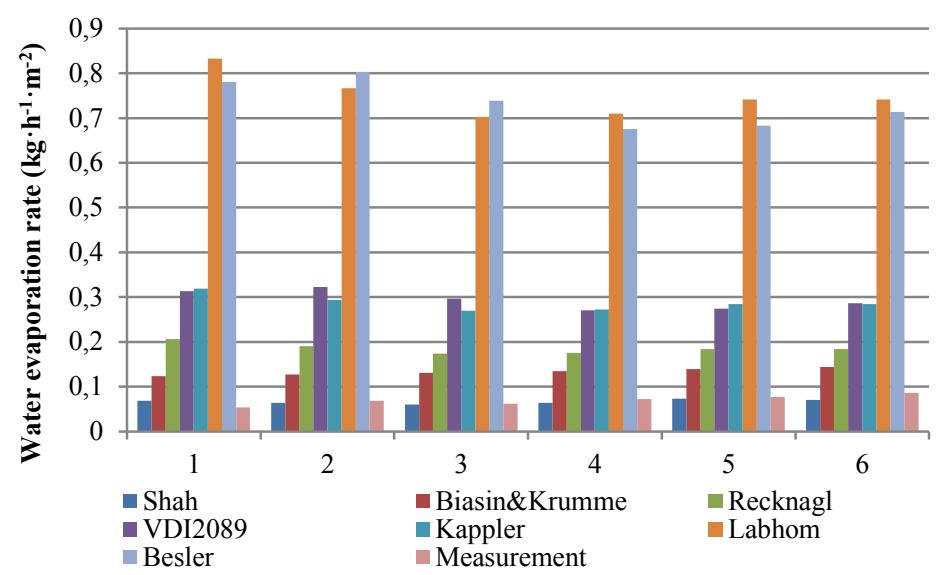

Fig. 4. Water evaporation rate in occupied sports swimming pools, depending on intensity of use, with conditions described above.

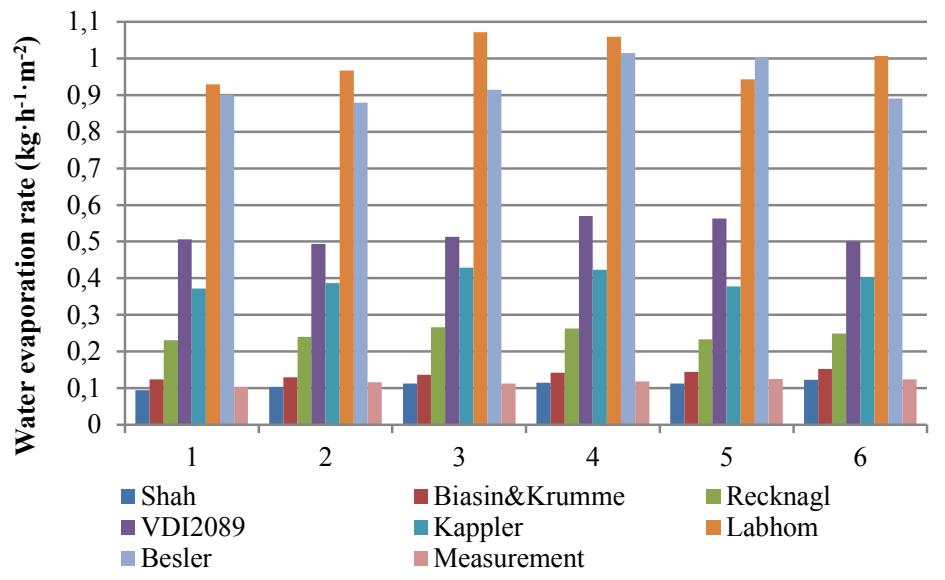

Fig. 5. Water evaporation rate in unoccupied recreational swimming pools, depending on intensity of use, with conditions described above.

\section{Conclusions}

Based on the results obtained during study, it was found that Shah and Biasin \& Krumm models were the best fitted to results of measurements in laboratory conditions, both in unoccupied and occupied swimming pools. At high air and water temperatures the indicated equations show better fit to experimental data. The underestimate was up to $12 \%$ for Shah model and to $18 \%$ for Biasin \& Krumm equations. In case of sports swimming pools conditions the differences was higher. The overestimate for unoccupied pools was similar for both equations and it was equal to $32 \%$. For occupied pools during low intensity of use the calculated water evaporation rates was higher about $22 \%$ for Shah equation and even $57 \%$ for Biasin \& Krumm model. When the intensity of use increased the overestimation of indicated both equations decreased. For Biasina \& Krumm, the overestimation was $40 \%$ at maximum measured intensity, and for Shah's equations at maximum measured intensity overestimation turned into underestimation about $22 \%$ ).

On the basis of conducted measurements for further analysis and calculations of vapor production are recommended equations published by Shah (9) and (19-21). 


\section{References}

1. Swimming pools in Poland, Prepared by the Ministry of Sport and Tourism, Warsaw, 2015, p. 165. (in Polish)

2. K. Ratajczak, E. Szczechowiak, Heating Engineering Heating Ventilation, 41, 4 (2010) 141-148 (in Polish)

3. F. Asdrubali, Energy and Buildings, 41 (2009) 311-319

4. M. Moghiman, A. Jodat, Iranian Journal of Mechanical Engineering, 8, 1 (2007) 19-30

5. R. Tang, Y. Etzion, Building and Environment, 39 (2004) 77-86

6. K. Ratajczak, E. Szczechowiak, CLIMA 2016 - proceedings of the 12th REHVA World Congress: volume 5. Aalborg: Aalborg University, Department of Civil Engineering.

7. C. C. Smith, C. O. G. Lof, R. W. Jones, ASHRAE Transactions , 99, 2 (1993) 864-874

8. M. M. Shah, Energy and Buildings, 49 (2012) 306-309

9. E. Sartori, Solar Energy, 68, 1 (2000) 77-89

10. M. Malicki, Ventilation and air conditioning, PWN, Warsaw 1980 (in Polish)

11. J. Ferencowicz, Wentylacja i Klimatyzacja, PWN 1974

12. H. Recknagel, E. Sprenger, Compendium of Heating and Air Conditioning, Omni Scala Wroclaw 2008 (in Polish)

13. M. Jaskólski, Z. Micewicz, IPPU MASTA, Gdańsk 2000 (in Polish)

14. M. M. Shah, Energy and Buildings, 35 (2003)

15. C. C. Smith, C. O. G. Lof, R. W. Jones, Solar Energy, 53 (1994)

16. G. Besler, Heating Engineering Heating Ventilation, 5 (1972)

17. H. Recknagel, E. Sprenger, Heating and air conditioning. Guide, Arkady, Warsaw 1994

18. M. M. Shah, Heating Piping Air Conditioning Engineering, 76 (2004) 